\title{
АНАЛИЗ ЭФФЕКТИВНОСТИ ПАЦИЕНТОЦЕНТРИЧНЫХ КОММУНИКАТИВНЫХ НАВЫКОВ ВРАЧА
}

\section{Макарова О.В.}

Цель. Представить критерии определения эффективности коммуникации врача с пацичентом.

Материалы и методы. Материалом исследования являются данные эксперимента, проведенного в ноябре 2020 года, и теоретические положения работ по теории коммуникации. Методом опроса 300 студентов ТюмГМУ были зафиксированы ситуации эффективной и неэффективной коммуникации с пациентами. На основе количественного и качественного анализа этих ситуаций были разработань критерии эффективности коммуникативных навыков врача.

Результаты. В ходе эксперимента были выявлены основные коммуникативные ошибки врача: неудачное использование профессионального жаргона, узкоспецииальной терминологии; нарушение этических принципов; неправильная аргументация; низкая эмпатия и другие.

Гуманизация современной медицинь и изменение статуса больного обусловили переход к новой модели лечения - пацчиентоориентированной, когда подразумевается, что заболевание может иметь биопсихосоциальный характер, а процесс лечения соотносится с принципами теории коммуникации. Мы предлагаем критерии определения эффективности коммуникации врача с паџиентом, основными параметрами которой являются: следование определенной коммуникативной стратегии (информирования, воздействия и др.) в соответствии с ситуациией общения; установление типа общения (открытого, инициитивного и др.); соответствие нормам культуры речи; соблюдение этикетных норм; осознание сочиальной роли, реализуемой врачом; трансакционный анализ общения с пацчентом; следование законам общения (закону зависимости результата общения от объема коммуникативных усилий; речевого поглощения эмоции); соблюдение врачом принцчипов бесконфликтного общения (благоприятной самоподачи; терпимости к собеседнику); использование приемов речевого воздействия. 
Заключение. Эффективная коммуникация врача возможна при условии осмысленной организации диалога с паџиентом.

Ключевые слова: теория коммуникации; эффективная пациентоцентричная коммуникация врача; коммуникативная компетентность врача.

\section{THE ANALYSIS OF DOCTOR'S PATIENT-CENTERED COMMUNICATION SKILLS EFFICIENCY}

\section{Makarova O.V.}

Background: Find out the efficiency criteria of doctor's patient-centered communication skills.

Materials and methods: Research is based on the results of the experiment, took place in November, 2020 and ideas of communication theory. 300 students of Tyumen State Medical University were interviewed to find the efficient and inefficient variants of doctor-patient communication. Basing on the quantitative and qualitative analysis of poll results, main criteria for evaluating the efficiency of patient-centered communication were found out.

Results: During the experiment main communicative mistakes were found out: unproper using of professional jargon, highly specialized terms, violation of ethical principles, wrong argumentation, low empathy etc.

Humanization of modern medicine and changing of patient status consider transition to the patient-centered model of curing, which suppose that any disease has biopsychosocial nature, and its curing requires following communication theory principles. We suggest the criteria for estimating of doctor's patient-centered communication efficiency, based on several features: following communication strategy (informing, impact etc.) corresponding to the current situation; searching for appropriate style of conversation (open, initiative etc.); compliance with standards of speech etiquette; awareness of the doctor social role; transaction analysis of communication with patient, following its laws, such as interdependence between communication result and expended efforts, speech absorption of emotions; creating nonconflicted communicative situation (favorable self-presentation and tolerance); using skills of speech impact.

Conclusion: Effective doctor's communication efficiency is based on deliberate organization of the dialog with patient.

Keywords: communication theory; effective patient-centered communication of the doctor; doctor's communicative competency. 
Поскольку медицинский дискурс является частью коммуникативной деятельности, обусловленной социальными целями, то актуальным является исследование данного феномена с точки зрения эффективности и способов речевого поведения участников общения.

Коммуникативная компетентность врача - одно из условий эффективной профессиональной деятельности. Как отмечают специалисты в области медицинской риторики, эффективность коммуникации врача в рамках делового общения на $80 \%$ зависит от коммуникативных навыков и только на $20 \%$ - от узкой профессиональной подготовки [1;2].

Цель исследования - представить критерии анализа эффективности пациентоцентричных коммуникативных навыков врача.

Ситуация, в которой пациент испытывает неудовлетворенность процессом общения с врачом, сегодня является стандартной. Несмотря на большое количество медцентров и альтернативных клиник с высокой стоимостью оказываемых медицинских услуг, далеко не всегда сотрудники в них обладают пациентоцентричными коммуникативными навыками, необходимыми для эффективной профессиональной деятельности. Хотя еще со времен Авиценны известен тезис, что у врача есть три вида оружия: растение, нож и слово.

Коммуникативные ошибки в общении с пациентами, с точки зрения медиков, не считаются существенными для успешной диагностики или лечения больного, поэтому врачи зачастую не придают им большого значения до тех пор, пока не возникнет конфликтной ситуации. Так, 84\% врачей-неврологов считают, что одной из самых существенных причин конфликтов с пациентами является «неумение врача найти с ними «общий язык» (77\%) [3, с. 169-173].

Рассмотрим реальную ситуацию: (на приеме у нефролога): Врач (далее В.): У вас был гестоз во время беременности? Пациент (далее - П.): А что это значит? В.: Раз не знаете, значит, не было. Допустив коммуникативную ошибку - нецелесообразное использование узкоспециальной терминологии, врач не только нарушил этические принципы (требование сохранения достоинства пациента, сославшись на его безграмотность), но и, скорее всего, допустит ошибку в постановке диагноза: незнание пациентом термина, еще не означает отсутствия заболевания, которое обозначено этим научным понятием.

Для медиков слово - важнейший инструмент, который может играть роль терапевтического средства или, наоборот, способствовать ухудшению состояния здоровья. Нарушение биопсихосоциального подхода к здоровью пациента приводит к негативному эффекту в профессиональной коммуникации. В современных условиях работы, когда пациенты хорошо зна- 
ют свои права, недопустимо нарушение врачом коммуникативных норм.

В целях изучения коммуникативных способностей врачей мы провели эксперимент «Пациентоцентричный подход в профессиональной деятельности врача». В исследование были вовлечены 300 студентов лечебного факультета, обучающихся на 1-ом курсе Тюменского государственного медицинского университета. На первом этапе нашего проекта мы опросили студентов в возрасте от 17 лет до 21 года (эти взрослые люди в соответствии с возрастной периодизацией в медицине относятся к юношескому периоду развития человека). Аудитория студентов является различной по гендерному признаку, что также важно для повышения релевантности полученных результатов.

В дальнейшем мы планируем опросить различные возрастные группы профессионального медицинского сообщества, так как именно этот вид респондентов может максимально многоаспектно оценить изучаемый тип коммуникативной ситуации. Врач является ведущим коммуникатором в диалоге с пациентом, именно он осуществляет отбор языковых, психологических, невербальных и других средств для достижения максимального коммуникативного эффекта. Кроме того, исследуя различные возрастные группы - от будущих врачей до практикующих, мы проследим динамику развития коммуникативных способностей у медиков на разных уровнях владения профессиональными навыками.

Вопросы в анкете составлены в соответствии с логикой изучения любого вида человеческой деятельности, в том числе процесса коммуникации врача и пациента. Так, для определения эффективности деятельности необходимо соотнести ее цель и средства, оптимальный выбор которых и реализация в совокупности способствуют достижению планируемого эффекта.

Первый вопрос эксперимента касался сбора эмпирического материала: респондентам предлагалось описать ситуации эффективной и неэффективной коммуникации с врачом, опираясь на свой опыт общения с ним в роли пациента. Выяснилось, что каждый информант, или $100 \%$ участников, довольно легко может привести такую ситуацию и подробно ее описать. Следовательно, проблема в полной и эффективной реализации врачом коммуникативного потенциала актуальна.

Далее респондентам было предложено назвать тип описанной коммуникативной ситуации: первичный/повторный прием, консультативный прием, обход в стационаре. Получение этой информации необходимо для выявления особенностей той или иной ситуации.

Задача третьего вопроса исследования - «Какую цель ставил врач (получить информачию, воздействовать/убедить, информировать, выразить 
сочувствие, установить контакт, поддержать имидж и др.)?»-выяснить основное коммуникативное намерение врача в описанной студентом профессиональной ситуации, влияющее не только на содержательный аспект диалога, но и на его композиционный рисунок.

Выяснилось, что врач ставит цель в зависимости от типа ситуации. Указание в ответе на несколько целей обусловлено тем, что, с одной стороны, коммуникативная ситуация может меняться в процессе диалога, с другой стороны, сама коммуникация с пациентом, как правило, многоаспектна: начальной стадии, как правило, соответствует фатическая цель, самопрезентация, завершающей - позитивизация информации, вразумления. Врач реализует сразу несколько коммуникативных намерений, при этом можно выделить ведущее.

На вопрос «Считаете ли вы эту коммуникативную ситуацию эффективной или неэффективной?»- мы получили следующие результаты. $67 \%$ опрошенных считают, что их диалог с врачом был бессмыслен, коммуникация неэффективна: они не получили удовлетворения и лечились либо по своему усмотрению (народные советы, информация из открытых Интернет-ресурсов), либо у другого специалиста. $33 \%$ респондентов считают, что врач достиг поставленной цели, правильно построил диалог: пациент следовал его рекомендациям и достиг выздоровления, следовательно, коммуникация была эффективной.

Далее мы предложили респондентам выбрать те средства, которые, на их взгляд, преимущественно способствуют эффективности или неэффективности коммуникации с врачом: языковые средства (лексические, грамматические, стилистические), средства убеждения (аргументы эмоциональные/ рациональные), психологические средства (принципы общения, взаимодействия), риторические средства (речевые приемы), невербальные средства (тон, интонация, темп речи, дистанция, жесты, поза, мимика и др.).

Анализ результатов пятого вопроса показал, что неэффективная коммуникация возникает в результате следующих коммуникативных ошибок врача: неудачное использование профессионального жаргона или узкоспециальной терминологии (34\%) (собачья мышиа - профессионализм, использованный врачом в ситуации, когда у пациента боли в области рта); нарушение этических принципов (оскорбление пациента, нанесение ущерба его эмоциональному состоянию (22\%): В.: Как вы питаетесь?.. Кофе какой пьете? П.: Растворимый. В.: Вот и травите себя, если так хочется, грудного ребенка такой гадостью кормить нельзя); невербальные ошибки (17\%) (сморщиться при осмотре, исключить контакт глаз, 
отвернуться от паџиента); нарушение прав пациента (9\%), ссылка на его возраст без желания разобраться в ситуации (П.: У меня сердие болит, давление скачет, печень беспокоит. В.: Ну, что Вы хотите, Вам же столько лет!); низкая эмпатия (8\%) и другие коммуникативные недочеты (10\%): речевые ошибки, несоблюдение принципов речевого общения (давление на пациента, отсутствие паритетности), неумение делать психологический анализ ситуации, определять тип личности пациента.

Помимо выявленных нами коммуникативных ошибок в медицинском дискурсе, отметим еще общепризнанные исследователями в области коммуникативного подхода в лечении: 1) неудачно организованный диалог, на основе которого, по данным статистики, можно диагностировать до $60 \%$ заболеваний; 2) формализм общения с пациентом; 3 ) нежелание выслушать пациента; 4) несоблюдение последним рекомендаций врача, или приверженности лечению [4; 5; 6]. Для большинства заболеваний адекватным уровнем приверженности является показатель не менее 80\% [7, с. 38]; 5) недостаточная разработанность теории коммуникативной компетентности врача $[8 ; 9 ; 10]$. Rita Charron пишет: «Пациенты обнаруживают, что ... они получают технически адекватное лечение, но остаются наедине с последствиями лечения и страхом перед болезнью. Научно обоснованная медицина в одиночку не может помочь больному справиться с утратой здоровья и найти значение болезни и смерти» [11]. Кроме того, исследования показали, что среднее время, которое врач тратит на то, чтобы выслушать пациента до того, как прервать его рассказ, составляет 16 секунд. R Simpson отмечает, что «с точки зрения пациента эта ситуация настораживающая: в отношении его здоровья принимаются серьёзные решения, а его никто не слушает» [12, с. 35].

Ощущение неудовлетворенности от общения с медиком не исчезает даже после успешного лечения. Пациент всерьез задумывается о том, чтобы поменять врача, даже такого, который хорошо лечит, но не умеет выстраивать эффективную коммуникацию.

Очевидно, что сегодня коммуникативные стратегии, используемые врачом, претерпели изменения: безусловный приоритет биологических факторов при оценке состояния пациента уступил место психосоциальным, или гуманистическим принципам медицины.

Врачи признают важность приобретения новой информации и необходимость освоения техническими навыками в рамках своей профессиональной деятельности, но часто уделяют меньше внимания обучению эффективному общению, особенно в сложных ситуациях, таких как: помощь пациентам в 
выборе правильного решения, выявление ошибок в процессе лечения или сообщение особого диагноза. Они также не рассматривают коммуникативные компетенции как навык, которому нужно учиться. В связи с этим необходимы существенные изменения в подготовке врачей, прежде всего, новые подходы должны быть более ориентированы на пациента.

Пациентоцентричный подход, включающий в себя слушание и понимание, подразумевает, что проблема в лечении может носить психо-духовный или социальный характер, и представлять собой комбинацию причин. В биомедицинской модели диагноз, как правило, делается в патолого-физиологических терминах. В случае, когда подход сконцентрирован на пациенте, болезнь описывается в терминах проблем, которые заметил сам пациент, его словами и внутри его собственных ощущений [12, с. 36-37]. Понимание истинного содержания рассказа о состоянии здоровья является первым основным требованием для его изменения и проходит в основном через изложение своей истории.

Процесс лечения - это прежде всего общение, диалог, а уже потом история болезни, осмотр, обследования, процедуры, лекарства и т.д. Мы согласны с В. Леви в том, что «сегодня медицина технизирована, химизирована, коммерциализирована. А больные ... хотят живого общения и непосредственного влияния, как в старомодные времена, хотят видеть во враче Человека, которому Можно Верить... А есть ведь еще те, кто ... хотят быть не только потребителями, но и сотворцами своего здоровья» [13, с. 16-19].

Опираясь на данные эксперимента, предлагаем следующие критерии анализа эффективности коммуникации врача с пациентом:

1. Следование определенной коммуникативной стратегии в соответствии с ситуацией общения.

Стратегия (информирования, внушения, убеждения и др.) реализуется в процессе достижения тех или иных коммуникативных целей говорящего.

Так, стратегия информирования реализуется при условии, что врач в диалоге ставит когнитивную (изменение картины мира пациента, экспликация информации из памяти, касающейся этиологии заболевания (например, при помощи наводящих вопросов), коммуникативную цели. В любой ситуации общения ведущим намерением является коммуникативная цель (получение информации, информирование, рекомендация, объяснение, аргументация).

Реализация коммуникативных намерений врача зависит от типа коммуникативной ситуации. В ситуации первичного приема врач ставит следующие цели: контактоустанавливающую; коммуникативную (собрать анамнез, выявить характер заболевания); прагматическую (сформировать 
и поддержать имидж). На повторном приеме врач ставит, прежде всего, дискурсивную цель (коррекция лечения, аргументация) и когнитивную. Во время обхода (в стационаре) - дискурсивную и коммуникативную цели; на консультативном приеме - коммуникативную, прагматическую.

При определении коммуникативных намерений мы используем классификацию, предложенную исследователями медицинского дискурса [14; $15 ; 16 ; 17]$.

2. Установление определенного типа общения (открытое/закрытое, инициативное/принудительное, официальное/неофициальное, этикетное/ свободное и т.д.), происходящего между участниками коммуникации.

Так, в ситуации первичного приема общение имеет открытый характер, если предметом диалога является пациент, его проблемы и эмоции, которого слушают и слышат. Общение считается инициативным при условии, что врач эмоционально привлекателен для собеседника. Официальный характер общения с пациентом устанавливается, если врач сохраняет социальную дистанцию, общается на Вы, выбирает нормированные варианты в речи. Такой тип общения, как правило, способствует более эффективному воздействию на пациента.

3. Соответствие нормам культуры речи.

Как правило, врач считается элитарным представителем речевой культуры. Наличие речевых ошибок в речи медика вызывает сомнение в его компетентности и отрицательно сказывается на имидже врача. Кроме того, неуместное использование терминологии, профессионализмов способствует еще и нарушению этических принципов общения. Приведем некоторые ошибки: орфоэпические: инщиНдент (вставка лишнего звука), дОговор (вместо догов $O p$ ); орфографические: педиатОра (вместо педиатра), лексические: коллега по работе (вместо коллега, сотрудник), клиническая картина протекает легко (вместо Клиническая картина выглядит ... / Заболевание протекает легко); грамматические: едьте (вместо поезжайте), прополоскайте горло (вместо прополощите), более красная слизистая (вместо темно-красная), не махайте руками (вместо - машите) и др.

4. Соблюдение этикетных норм на уровне речи и этикета поведения.

Речевой этикет подразумевает использование стандартных формул приветствия, прощания. Сюда также можно отнести умение врача преодолевать агрессию собеседника - пациента, испытывающего стресс, боль, страхи и, как следствие, уязвимого и склонного к конфликту. Если врач умеет заменять агрессивные высказывания на альтернативные, соответствующие этикетным речевым жанрам, то его коммуникативная компетенция повышается. 
Таблица 1.

Способы преодоления речевой агрессии

\begin{tabular}{|l|l|}
\hline \multicolumn{1}{|c|}{$\begin{array}{c}\text { Типы агрессивных } \\
\text { высказываний }\end{array}$} & \multicolumn{1}{|c|}{$\begin{array}{c}\text { Этикетные речевые жанры } \\
\text { и жанровые разновидности }\end{array}$} \\
\hline Оскорбление & Извинение \\
\hline Насмешка, колкость & Комплимент, похвала \\
\hline Грубое толкование & Вежливая просьба \\
\hline Грубый отказ & Вежливый отказ \\
\hline Угроза & Предупреждение, напоминание \\
\hline Ссора & Спор, дискуссия \\
\hline
\end{tabular}

Кроме того, этикет поведения медика соответствует этическому кодексу врача, если соотносится с основными положениями, сформулированными еще в клятве Гиппократа: непричинение вреда больному, милосердие, доминанта интересов больного, уважение жизни и отрицательное отношение к эвтаназии, неразглашение врачебной тайны и др.

5. Осознание социальной роли, реализуемой врачом в конкретной ситуации.

В ситуации врачебного приема роль первого участника ситуации (X-врача) выше роли второго участника ситуации (Ү-пациента): P X > P Y, так как $\mathrm{Y}$ зависим от $\mathrm{X}$-а (опираемся на схемы взаимодействия, предложенные Л.П. Крысиным [18]). Если врач больше внимания уделяет собственной речи в ситуации общения, то следует не только нормам строгого литературного языка, но и требованию коммуникативной целесообразности речи.

6. Анализ взаимодействия с пациентом, или трансакционный анализ, структура которого предложена Э.Берн [19].

В соответствии с таким видом анализа врач часто занимает позицию «Родитель», а пациент - роль «Дитя». Такая модель отношений не всегда эффективна. Оптимальной является модель «Взрослый» - «Взрослый», которая предполагает технологию сотрудничества.

7. Использование врачом косвенных высказываний. Такая особенность речи врача способствует ее некатегоричности, например: В.: Bbl не могли бы показать ваш язык? - косвенный речевой акт просьбы, его содержание может быть понято в результате единичного высказывания, изолированного от контекста - Покажите мне язык!; В.: Вам не холодно? - косвенный речевой акт предложения закрыть окно. В условиях нехватки времени и постоянного стресса врач часто не отбирает выражения эвфемистического характера (например, говорит «импотенция» вместо нарушение половой 
функции; «операция» вместо хирургическое вмешательство. Речь врача часто является категоричной, что, безусловно, снижает уровень эффективности коммуникации, с точки зрения пациента.

8. Следование законам общения. Эффективность коммуникации с пациентом напрямую зависит от психологического аспекта речи. Назовем некоторые важные законы общения: закон зеркального развития общения: П.: Плохо... В.: Да, плохо...; закон зависимости результата общения от объема коммуникативных усилий: врач не жалеет сил и времени на уговоры; закон отражения (врач развивает мысль собеседника); закон речевого поглощения эмоции (пациент выговаривается перед врачом, жалуется ему).

9. Контроль за невербальным поведением врача. Данный критерий эффективности, связанный с соблюдением социальной дистанции, обеспечением визуального контакта и другими паралингвистическими средствами, довольно подробно описан во многих работах $[20 ; 21]$ и является одним из существенных в медицинском дискурсе.

10. Соблюдение врачом универсальных принципов бесконфликтного общения. Известный исследователь в области теории коммуникации И.А. Стернин, называет ряд таких принципов [22], при этом ситуации общения врача с пациентом соответствуют следующие: принцип благоприятной самоподачи (врач показывает себя заботливым, внимательным человеком, соблюдающим все нормы уважения); принцип терпимости к собеседнику; минимизации негативной информации (врач соблюдает данный принцип, если дает информацию, способную вызвать активное неприятие, в конце разговора, в полувопросительной форме, предварительно подготовив собеседника).

11. Использование приемов речевого воздействия. Данный критерий подразумевает учет пола собеседника, его возраста, уровня образования и других особенностей пациента. Так, в диалоге с женщиной врач более эмоционален, может использовать фигуры речи (контраста, иронии). Чтобы воздействовать на лиц старшего поколения, врач внимательно выслушивает; поддерживает мнение пожилого пациента, обращается по имени-отчеству.

Таким образом, представленные выше критерии, способствующие повышению эффективности коммуникации с пациентом, на наш взгляд, будут полезны в случае осознания врачом, что осмысленная, структурированная беседа с больным - необходимое условие его лечения. Ввиду перехода на партнёрскую модель взаимодействия с пациентом необходима корректировка сложившихся норм речевого взаимодействия в процессе общения доктора и пациента и усовершенствование системы подготовки будущих врачей. 


\section{Список литературы}

1. Чертков Ю. Медицинская риторика как высокоэффективный терапевтический и коммуникативный инструмент // Агентство медицинского маркетинга. URL: https://amm.net.ua/med-r.html (дата обращения: 11.12.2020).

2. Гринько Е.Н. Медицинская риторика в подготовке врачей-педиатров // Вопросы современной педиатрии. 2016. 15 (3). С. 235-238.

3. Голева Е.В. Анализ ошибок и осложнений в неврологической клинике при лечении больных с геморрагическими инсультами: Дис. ... канд. мед. наук. M., 2008. 233 c.

4. Микиртичан Г.Л., Каурова Т.В., Очкур О.К. Комплаентность как медикосоциальная и этическая проблема педиатрии // Вопросы современной педиатрии. 2012. Т. 11. № 6. С. 5-10.

5. Clark P.A. Medical practices' sensitivity to patients' needs: Opportunities and practices for improvement // Journal of Ambulatory Care Management. 2003, vol. 26(2), pp. 110-123. doi: 10.1097/00004479-200304000-00004

6. Assessing competence in communication and interpersonal skills: The Kalamazoo II report / F.D. Duffy [et al.] // Academic Medicine. 2204, vol. 79(6), pp. 495-507. doi: 10.1097/00001888-200406000-00002

7. Лаписа С.В., Седиванова Т.В. Эффективная коммуникация в системе «врач-пациент» и формирование комплаенса // Врач-пациент: сотрудничество в решении проблем здоровья: электронный сборник, 2017. С. 37-42. URL: http://elib.grsmu.by/bitstream/handle/files/5176/37-42\%20z. pdf? sequence $=1 \&$ isAllowed $=\mathrm{y}$

8. Цветкова Л.А. Коммуникативная компетентность врачей-педиатров. Автореф. дис. ... канд. псих. наук. Санкт-Петербург, 1994. 23 с.

9. Васильева Л.Н. Коммуникативная компетентность в профессионально-личностном становлении будущего врача. Автореф. дис. ... канд. псих. наук. Кострома, 2010. 23 с.

10. Сударева О.Ю. Анализ затруднений в профессиональном общении врача-педиатра // Вестник Российского нового университета. 2013. № 1 С. 89-93.

11. Charron R. Narrative Medicine: Honoring Stories of Illness. Oxford: Oxford University, 2006. 304 pp.

12. Симпсон Р. Диалог врача и пациента // Земский врач. № 7(12). 2011. С. 35-37.

13. Леви В.Л. Ошибки здоровья. М.: Торобоан, 2004. 416 с.

14. Барсукова М.И. Речевые стратегии и тактики медицинского дискурса // Античный мир и мы: мат-лы конф. Саратов: Изд-во ГОС УНЦ «Колледж», 2005. Вып. 10. С. 40-46.

15. Жура В.В. Виды коммуникативного взаимодействия врача и пациента // Вестник ВолГМУ. 2004. №. 10. С. 84-88. 
16. Акаева Э.В. Коммуникативные стратегии профессионального медицинского дискурса: автореф. ... дис. канд. филол. наук. Омск, 2007. 21 с.

17. Бейлинсон Л.С. Характеристики медико-педагогического дискурса (на материале логопедических рекомендаций): дис. ... канд. филол. н. Волгоград, 2001. 187 с.

18. Крысин Л.П. Социальный аспект владения языком // Крысин Л.П. Социолингвистические аспекты изучения современного русского языка. М., 1989. С. $120-164$.

19. Берн Э. Игры, в которые играют люди: Психология человеческих взаимоотношений; Люди, которые играют в игры: Психология человеческой судьбы / Пер. с англ. М.: Прогресс, 1988. 399 с.

20. Болучевская В.В., Павлюкова А.И. Общение врача: вербальная и невербальная коммуникация. (Лекция 2) // Медицинская психология в России: электронный журнал, 2011. № 2. URL: http://medpsy.ru (дата обр.: 10.12.2020).

21. Street, R. L., \& Buller, D. B. Nonverbal response patterns in physician-patient interactions: A functional analysis // Journal of Nonverbal Behavior. 11(4). 1987. PP. 234-253. doi: 10.1007/BF00987255

22. Стернин И.А. Введение в речевое взаимодействие. Воронеж, 2001. 237 c. URL: https://www.vsu.ru/ru/university/structure/communicate/pdf/monographs/verbal-infl_2001.pdf

\section{References}

1. Chertkov Yu. Meditsinskaya ritorika kak vysokoeffektivnyy terapevticheskiy i kommunikativnyy instrument [Medical rhetoric as a highly effective therapeutic and communicative tool]. Agentstvo meditsinskogo marketinga [Medical Marketing Agency.]. https://amm.net.ua/med-r.html (accessed December 11, 2020).

2. Grin'ko E.N. Meditsinskaya ritorika v podgotovke vrachey-pediatrov [Medical rhetoric in the training of pediatricians]. Voprosy sovremennoy pediatrii [Questions of modern pediatrics], 2016, vol. 15, no. 3. pp. 235-238.

3. Goleva E.V. Analiz oshibok i oslozhneniy v nevrologicheskoy klinike pri lechenii bol'nykh s gemorragicheskimi insul 'tami [Analysis of errors and complications in a neurological clinic in the treatment of patients with hemorrhagic strokes]: Dis. ... kand. med. nauk. Moscow, 2008. 233 p.

4. Mikirtichan G.L., Kaurova T.V., Ochkur O.K. Komplaentnost' kak medikosotsial'naya i eticheskaya problema pediatrii [Compliancy as a medico-social and ethic problem of pediatrics]. Voprosy sovremennoy pediatrii [Current pediatrics], 2012, vol. 11, no. 6. pp. 5-10.

5. Clark P.A. Medical practices' sensitivity to patients' needs: Opportunities and practices for improvement. Journal of Ambulatory Care Management. 2003, vol. 26, no. 2. pp. 110-123. doi: 10.1097/00004479-200304000-00004 
6. Assessing competence in communication and interpersonal skills: The Kalamazoo II report / F.D. Duffy [et al.] Academic Medicine, 2004, vol. 79, no. 6. pp. 495-507. doi: 10.1097/00001888-200406000-00002

7. Lapisa S.V., Sedivanova T.V. Effektivnaya kommunikatsiya v sisteme «vrach-patsient» i formirovanie komplaensa [Effective communication in the "doctor-patient" system and the formation of compliance]. Vrach-patsient: sotrudnichestvo $v$ reshenii problem zdorov'ya: elektronnyy sbornik [Doctor-patient: cooperation in solving health problems], 2017, pp. 37-42. http://elib.grsmu.by/bitstream/ handle/files $/ 5176 / 37-42 \% 20 \mathrm{z} . p d f$ ?sequence $=1 \&$ isAllowed $=\mathrm{y}$

8. Tsvetkova L.A. Kommunikativnaya kompetentnost'vrachey-pediatrov [Communicative competence of pediatricians]: dissertation abstract]. Sankt-Peterburg, 1994. $23 \mathrm{p}$.

9. Vasil'eva LN. Kommunikativnaya kompetentnost'v professional'no-lichnostnom stanovlenii budushchego vracha [Communicative competence in the professional and personal development of a future doctor]: dissertation abstract. Kostroma, 2010. 23 p.

10. Sudareva O.Yu. Analiz zatrudneniy v professional'nom obshchenii vracha-pediatra [Analysis of difficulties in professional communication of a pediatrician]. Vestnik Rossiyskogo novogo universiteta [Bulletin of the Russian New University]. 2013, no. 1, pp. 89-93.

11. Charron R. Narrative Medicine: Honoring Stories of Illness. Oxford: Oxford University, 2006, $304 \mathrm{p}$.

12. Simpson P. Dialog vracha i patsienta [Dialogue between doctor and patient]. Zemskiy vrach [Zemsky doctor], 2011, no. 7(12), pp. 35-37

13. Levi V.L. Oshibki zdorov'ya [Health errors]. Moscow: Toroboan, 2004. 416 p.

14. Barsukova M.I. Rechevye strategii i taktiki meditsinskogo diskursa [Speech strategies and tactics of medical discourse]. Antichnyy mir i my: mat-ly konf. [Antique world and us: materials of the conf.], Saratov: Izd-vo GOS UNTs «Kolledzh», 2005, issue 10. pp. 40-46.

15. Zhura V.V. Vidy kommunikativnogo vzaimodeystviya vracha i patsienta [Types of communicative interaction between doctor and patient]. Vestnik VolGMU [Bulletin of VolGMU], 2004, no. 10, pp. 84-88.

16. Akaeva E.V. Kommunikativnye strategii professional'nogo meditsinskogo diskursa [Communication strategies of professional medical discourse]: avtoref. ... dis. kand. filol. nauk. Omsk, 2007. 21 p.

17. Beylinson L.S. Kharakteristiki mediko-pedagogicheskogo diskursa (na mat-le logopedicheskikh rekomendatsiy) [Characteristics of medical and pedagogical discourse (based on speech therapy recommendations): dis. ... kand. filol. nauk. Volgograd, 2001. $187 \mathrm{p}$. 
18. Krysin L.P. Sotsial'nyy aspekt vladeniya yazykom [Social aspect of language proficiency]. Krysin L.P. Sotsiolingvisticheskie aspekty izucheniya sovremennogo russkogo yazyka [Sociolinguistic aspects of studying the modern Russian language]. Moscow, 1989. pp. 120-164.

19. Bern E. Igry, v kotorye igrayut lyudi: Psikhologiya chelovecheskikh vzaimootnosheniy; Lyudi, kotorye igrayut v igry: Psikhologiya chelovecheskoy sud'by [Games that people play: Psychology of human relationships; People Who Play Games: The Psychology of Human Destiny]. Per. s angl. Moscow: Progress, 1988. 399 p.

20. Boluchevskaya V.V., Pavlyukova A.I. Obshchenie vracha: verbal'naya i neverbal'naya kommunikatsiya. (Lektsiya 2) [Physician communication: verbal and non-verbal communication. (Lecture 2)]. Meditsinskaya psikhologiya v Rossii: elektronnyy zhurnal [Medical psychology in Russia: electronic journal], 2011, no 2. http:// medpsy.ru (accessed December 10, 2020).

21. Street R.L., Buller D.B. Nonverbal response patterns in physician-patient interactions: A functional analysis. Journal of Nonverbal Behavior, vol. 11, no. 4, 1987, pp. 234-253. doi: 10.1007/BF00987255

22. Sternin I.A. Vvedenie v rechevoe vzaimodeystvie [Introduction to speech interaction], Voronezh, 2001. 237 p. https://www.vsu.ru/ru/university/structure/communicate/pdf/monographs/verbal-infl_2001.pdf (accessed December 7, 2020).

ДАННЫЕ ОБ АВТОРЕ

Макарова Ольга Владимировна, доцент кафедры филологических дисциплин, кандидат филологических наук, доцент

Тюменский государственный медиџинский университет ул. Одесская, 54, г. Тюмень, 625023, Российская Федераиия omakarova1980@mail.ru

\section{DATA ABOUT THE AUTHOR}

Makarova Olga Vladimirovna, Associate Professor, Department of Philological Disciplines, Ph. D. in Philology

Tyumen State Medical Academy

54, Odesskaya Str., Tyumen, 625023, Russian Federation

omakarova1980@mail.ru

SPIN-code: 5658-9943

ORCID: 0000-0002-3356-6794

ResearcherID: omakarova1980@mail.ru

Scopus Author ID: omakarova1980@mail.ru 